\title{
Degradation in Seawater of Structural Adhesives for Hybrid Fibre-Metal Laminated Materials
}

\author{
Cristina Alia, ${ }^{1}$ María V. Biezma, ${ }^{2}$ Paz Pinilla, ${ }^{1}$ José M. Arenas, ${ }^{1}$ and Juan C. Suárez \\ ${ }^{1}$ Center for Durability and Structural Integrity of Materials (CISDEM-UPM/CSIC), \\ Universidad Politécnica de Madrid, C/Ronda Valencia, 3-28015 Madrid, Spain \\ ${ }^{2}$ Research Group on Degradation and Corrosion of Materials, Universidad de Cantabria, c/Gamazo, 1-39004 Santander, Spain
}

Correspondence should be addressed to José M. Arenas; josemanuel.arenas@upm.es

Received 16 November 2012; Revised 15 January 2013; Accepted 22 January 2013

Academic Editor: Luigi Nicolais

Copyright (C) 2013 Cristina Alia et al. This is an open access article distributed under the Creative Commons Attribution License, which permits unrestricted use, distribution, and reproduction in any medium, provided the original work is properly cited.

\begin{abstract}
The adhesives used for applications in marine environments are subject to particular chemical conditions, which are mainly characterised by an elevated chlorine ion content and intermittent wetting/drying cycles, among others. These conditions can limit the use of adhesives due to the degradation processes that they experience. In this work, the chemical degradation of two different polymers, polyurethane and vinylester, was studied in natural seawater under immersion for different periods of time. The diffusion coefficients and concentration profiles of water throughout the thickness of the adhesives were obtained. Microstructural changes in the polymer due to the action of water were observed by SEM, and the chemical degradation of the polymer was monitored with the Fourier transform infrared spectroscopy (FTIR) and differential scanning calorimetry (DSC). The degradation of the mechanical properties of the adhesive was determined by creep tests with Mixed Cantilever Beam (MCB) specimens at different temperatures. After 180 days of immersion of the specimens, it was concluded that the $J$-integral value (depending on the strain) implies a loss of stiffness of $51 \%$ and a decrease in the failure load of $59 \%$ for the adhesive tested.
\end{abstract}

\section{Introduction}

Adhesives play a fundamental role in the manufacture and assembly of structural panels made from hybrid fibre/metal materials, which consist of layers of steel around a glass fibre fabric-reinforced vinylester matrix core [1]. These structural materials are used mainly in marine environments (such as ship hulls and offshore wind farms), in which they will be subjected to high relative humidities, temperatures, and chlorine ion concentrations-among other aggressive agents-over long periods of times. These conditions limit the use of adhesives due to the degradation processes that both the polymeric adhesive systems and the adherents themselves experience, which can lead to a deterioration of the mechanical properties of the assembly and ultimately result in the failure of the joint. In addition, water (liquid or vapour) is one of the most common damaging environmental agents to the durability of adhesive joints [24]. The majority of adhesive joints are exposed to water by high relative humidity, making it practically impossible to prevent water from diffusing into the interior of the adhesive. The temperature and humidity act jointly on the mechanical behaviour of the adhesive, synergistically accelerating the degradation processes of the adhesive joint. The mechanical properties of the polymeric materials change over time, especially when they are subjected to variable charge environments for a long period of time, making it extremely important to develop tests that accelerate the degradation process to better understand the deterioration of the joint's mechanical resistance under different environmental conditions $[5,6]$. Several studies on the degradation mechanisms of structural adhesives in air have been performed that conclude that the main cause of degradation is photooxidation [7-9]. However, the amount of available information on the degradation mechanisms of adhesives in humid conditions, specifically in a marine environment, is much more limited. Studies performed with epoxy resins [10-12] and polyurethane [13-15] have provided some clarification, but data on vinylester resins in the literature remain sparse [16]. 
Bowditch [17] described the diverse processes that influence the durability of polymeric adhesives in the presence of seawater; the most important of which were plasticisation, swelling, and hydrolysis. The absorption of water by the adhesive led to resin plasticisation, which reduces the joint strength; they also quantified the critical water content with the goal of relating this content to the adhesive chemistry. Burns et al. [18] determined the bulk module for natural elastomers, neoprenes, and polyurethanes after aging them for up to 2 years in artificial seawater, noting that the properties remained very stable during this period. Rutkowska et al. [13] examined the degradation of polyurethanes in the Baltic Sea water and in seawater with $\mathrm{NaN}_{3}$ for periods longer than 12 months. They characterised changes in the weight, tensile strength, and morphology of the polyurethane specimens after different periods of immersion in both environments and demonstrated that the degree of polymer degradation in seawater depended on the degree of cross-linking. The polyurethane-metal interface was studied by Possart [19], who showed that the bulk properties of the adhesive dominate its behaviour, when the polyurethane film exceeds a certain width but that the polymer chemistry is modified at distances very close to the interface, which decisively influences the detachment phenomena.

The time-dependent response of polymeric materials (viscoelastic behaviour) makes necessary the design of specific assays that permit the extrapolation of results obtained in the laboratory throughout the structural adhesive's useful life [20-23]. Davies et al. [20] used damage parameters to evaluate the influence of seawater on the aging of polymers using pattern curves based on the time-temperature equivalency principle. These results allowed them to understand the long-term evolution of the materials' rigidity and resistance properties under harsh environmental conditions.

This work is centred on the study of the degradation of polymers often used as structural adhesives, specifically the degradation behaviour of bulk specimens immersed in natural seawater. The specimens are fabricated with two different types of adhesives (a two-component polyurethane and a vinylester resin). The water diffusion coefficients for both adhesives were experimentally determined through gravimetric tests in test tubes with immersion times of up to 6 months. The loss of mechanical properties caused by aging has been determined using a slow flow (creep) tensile tests in a test station specifically designed and built for the purpose [24]. For this purpose, tests at different temperatures with Mixed Cantilever Beam (MCB) specimens have been carried. The loss along the time of the mechanical properties caused by degradation in seawater has been expressed as the decrease in the value of stiffness and failure load of the adhesive joint (in \% compared to specimens not immersed in seawater). The adhesive degradation mechanisms facilitated by seawater was studied using the Fourier transform infrared (FTIR) spectroscopy and differential scanning calorimetry (DSC). The postfracture mechanical specimens were also studied by optical microscopy and scanning electron microscopy (SEM) techniques to determine the types of failure that have occurred.
TABle 1: Properties of adhesives.

\begin{tabular}{lcc}
\hline & Polyurethane & Vinylester \\
\hline Tensile strength $(\mathrm{MPa})$ & 6 & 80 \\
Elongation at break $(\%)$ & 120 & 5 \\
Viscosity at $25^{\circ} \mathrm{C}(\mathrm{mPa} \cdot \mathrm{s})$ & 4500 & $520-620$ \\
Pot life at $25^{\circ} \mathrm{C}(\mathrm{min})$ & 10 & $14-24$ \\
\hline
\end{tabular}

\section{Experimental}

2.1. Materials. Two types of adhesives that are usually used in the manufacture of hybrid materials were selected for study: a two-component polyurethane adhesive and a vinylester resin. For this study, bulk adhesive specimens were manufactured with dimensions of $1.5 \times 15 \times 80 \mathrm{~mm}^{3}$ and were cured for 24 hours. The properties of these adhesives are shown in Table 1. Tests have been performed with specimens without introducing them in seawater (initial condition, $t=0 \mathrm{~s}$ ) and specimens immersed in seawater during independent periods of time (to study the diffusion of water into the adhesive with $1,2,3,8,16,32,64$, and 180 days of immersion).

2.2. Degradation upon Contact with Seawater. Water that comes into contact with the adhesive surface penetrates into the macromolecular network and diffuses at different velocities, depending on the polarity of the organic groups present and the degree of cross-linking (free volume) of the polymer. The temperature and $\mathrm{pH}$ of the aqueous medium also play an important role in the water diffusion and on the kinetics of the attack mechanisms on functional groups. When the percentage of water absorbed by the polymer is small, Fick's second law can be applied $[25,26]$ to calculate the diffusion coefficient of water in the resin:

$$
\frac{d C}{d t}=D \frac{d^{2} C}{d x^{2}}
$$

where $C$ is the concentration of seawater absorbed (\%); $t$ is the immersion time (s); $D$ is the diffusion coefficient of water in the adhesive $\left(\mathrm{m}^{2} \mathrm{~s}^{-1}\right) ; x$ is the depth of water penetration (m).

Absorbed fluid concentration $C(t)$ is usually expressed as the relative difference between the wet and dry masses of the specimen. That is,

$$
C(t)=\frac{M(t)-M_{0}}{M_{0}},
$$

where $M(t)$ is the mass of the specimen which has been immersed in water for a time $t$ and $M_{0}$ is the mass of dry specimen.

The Fick diffusion curve is the curve of concentration versus time. The apparent diffusion coefficient $D_{A}[25]$ can be calculated by applying it to the linear zone of Fick's diffusion curve, as shown in the following equation:

$$
D_{A}=\frac{\pi}{16}\left(\frac{h\left(C\left(t_{2}\right)-C\left(t_{1}\right)\right)}{C_{s}\left(\sqrt{t_{2}}-\sqrt{t_{1}}\right)}\right)^{2},
$$


where $C_{s}$ is the concentration of equilibrium or chemical saturation; $C\left(t_{1}\right)$ amount of fluid absorbed until the time $t_{1}$; $C\left(t_{2}\right)$ amount of fluid absorbed until time $t_{2} ; h$ thickness of the specimen in $\mathrm{m}$ ( $1.5 \mathrm{~mm}$ in our case).

The specimens were immersed in the Santander Bay (Spain) seawater, which had a $\mathrm{pH}$ of 8.2 at room temperature, for durations of $1,2,3,8,16,32,64$, or 180 days. The amount of water absorbed was determined through gravimetric analysis. The sequence of the degradation processes that occur upon immersion in seawater is shown in Figure 1.

The water absorbed by the polymer has been partially eliminated by vacuum drying the specimens. Drying is carried out by heating the specimens at a temperature of $40^{\circ} \mathrm{C}$ in a container where the vacuum has been done (0.053 Atm). The water that is chemically linked to the polar groups in the polymer will be retained after the vacuum drying and is responsible for the long-term degradation of the adhesive mechanical properties. The water that is not chemically linked temporarily modifies the polymer's properties, but these properties recover after its elimination during vacuum drying.

2.3. Analysis Methods. Several different techniques were used to follow the evolution of the polymer environmental degradation processes.

(i) For gravimetric analysis, an electronic scale, model SATRORIUS TE $214 \mathrm{~S}$, with a precision of $0.0001 \mathrm{~g}$ was used to measure the water uptake for determination of the adhesive diffusion coefficients.

(ii) The depth to which seawater has diffused into the adhesive joint was determined by a scanning electron microscope (SEM), model JEOL JSM 5600. The specimens were metalized with gold by sputtering in an argon atmosphere, and an electron acceleration voltage of $20 \mathrm{kV}$ was used for the imaging.

(iii) ATR-FTIR spectroscopy, model BRÜCKER TENSOR 27 , was used at room temperature in the 4000$525 \mathrm{~cm}^{-1}$ wavenumber range to study the chemical changes in the adhesive throughout the degradation process that is a result of extended exposure to seawater.

(iv) A differential scanning calorimeter (DSC), model SDT Q600, was used to observe the change in the glass transition temperature $\left(T_{g}\right)$ for the different degradation periods; the temperature range was from $0^{\circ} \mathrm{C}$ to $400^{\circ} \mathrm{C}$ under a nitrogen gas atmosphere, and the heating rate was $20^{\circ} \mathrm{C} / \mathrm{min}$.

(v) An IBERTEST IBTH3630 machine with a $200 \mathrm{~N}$ load cell and a movement rate of $2 \mathrm{~mm} / \mathrm{min}$ was used to characterise the property losses that the adhesive experiences as an effect of the degradation.

\section{Results and Discussion}

3.1. Diffusion Coefficients and Seawater Concentration Profiles. The diffusion coefficients of the adhesives were calculated using the gravimetric results obtained from the bulk adhesive specimens. In Figure 2, an initial period can be observed, in which the weight increases as a function of the time for which the specimen has been immersed because of the water absorption by the adhesive. These data were used to calculate the diffusion coefficient. From day 9 of immersion, the specimen weight begins to decrease due to the onset of the degradation phenomena in the polymer. We consider the concentration at which the weight maximum is reached to be the critical water level. In both adhesives and 9 days after the immersion, it was found that the weight of the specimen decreases. This occurs because the water attacks the polymer chains (which have operated since the beginning of immersion). These phenomena degrade irreversibly the adhesive because they produce bond breakage and loss of polymer fragments that pass to seawater.

From these data, the water diffusion coefficients of both polymers can be obtained. The fact that the adhesive specimen has 6 faces through which water can enter the polymeric network must be taken into consideration, making it necessary to use a correction factor to Fick's law to take into account the diffusion through the sides. Thus, the following expression is applied:

$$
D=D_{o}\left(1+\frac{h}{l}+\frac{h}{b}\right)^{-2}
$$

where $D$ is the water diffusion coefficient in the adhesive $\left(\mathrm{m}^{2} \mathrm{~s}^{-1}\right) ; D_{o}$ is the diffusion coefficient without considering water entry through the sides $\left(\mathrm{m}^{2} \mathrm{~s}^{-1}\right)$; lis the specimen length $(\mathrm{m}) ; b$ is the specimen width $(\mathrm{m}) ; h$ is the specimen thickness (m).

The measured diffusion coefficients for the adhesives are $6.39 \times 10^{-13}$ and $5.14 \times 10^{-13} \mathrm{~m}^{2} \mathrm{~s}^{-1}$ for polyurethane and vinylester, respectively. Once the diffusion coefficients are known, the concentration profiles of water in an adhesive joint with a given thickness can be obtained as a function of the immersion time. Thus, we can determine how long the water takes to diffuse into the centre of the adhesive joint and what amount of time is necessary for the water concentration in the central zone to exceed a critical value above which irreversible chemical changes occur, which result ultimately in the permanent loss of the mechanical properties of the joint. Bowditch [17] examined how water can affect the physical and mechanical properties of the adhesive and also the nature of the interface between it and the substrate. Bowditch considers the existence of a residual force at the joints (where the adhesive can be separated from the substrate by the action of water). He described the mechanisms that influence the durability of the polymeric adhesives in the presence of seawater. Datla et al. [28] examined the effect of mass adhesive samples subjected to different levels of humidity and $50^{\circ} \mathrm{C}$, and they concluded that the saturation level is increased with the relative humidity. They proposed a model of absorption in two stages. This model gave excellent results and was easily modeled with FEM.

The loss of mechanical properties in the adhesive joint was investigated with Mixed Cantilever Beam (MCB) specimens in composite mode. This specimen configuration, 


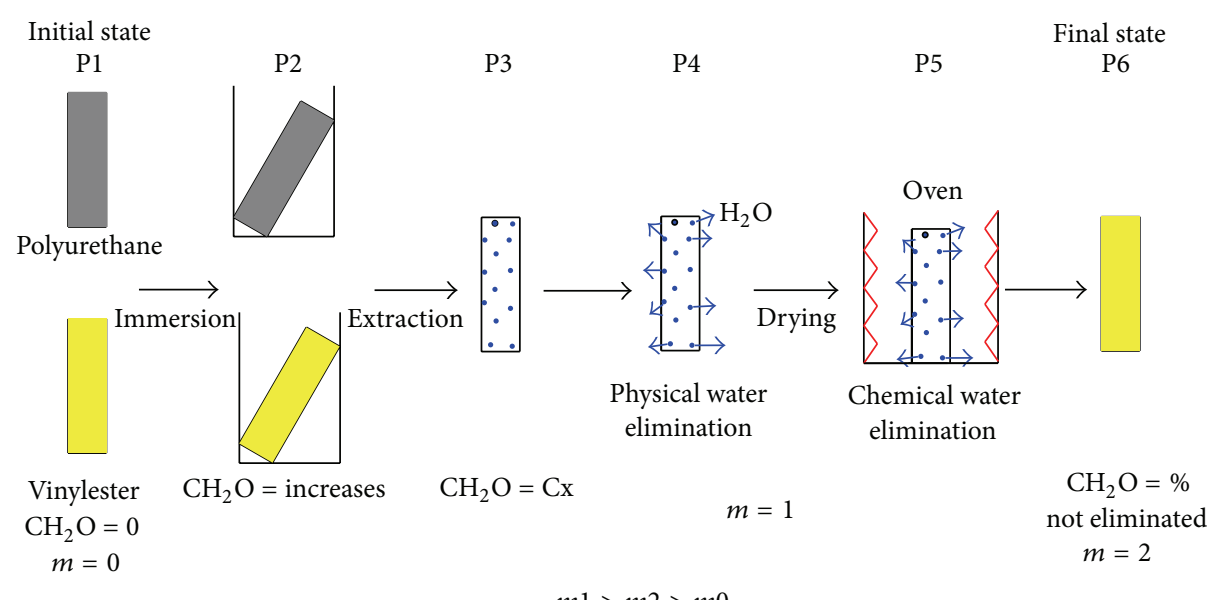

FIGURE 1: Degradation process.

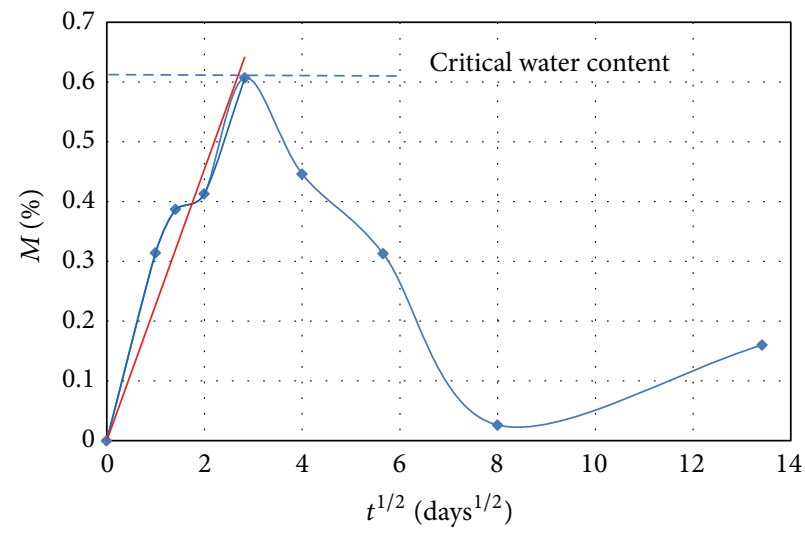

(a)

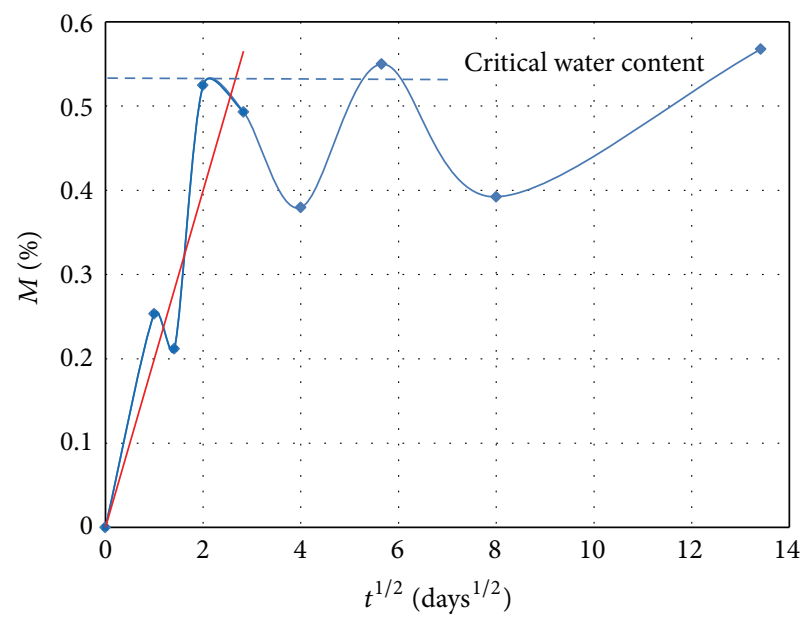

(b)

Figure 2: Water absorption curves as a function of specimen immersion time: (a) polyurethane and (b) vinylester.

proposed by Högberg and Stigh [29, 30], has advantages over other configurations commonly used in the study of the environmental degradation of adhesive joints.

The water concentration profiles as a function of immersion time were calculated using Fick's law and incorporated the geometry of the MCB specimens. Thus, the time needed for the centre of the specimen to reach the critical humidity level, the level required to cause irreversible damage to the polymer properties, can be determined. Times of 139 and 94 days for polyurethane and vinylester, respectively, were determined (Figure 3).

3.2. Scanning Electron Microscopy. The depth to which seawater has diffused into the adhesive joint was determined by SEM. It must be taken into account that water absorption occurs through all of the borders of the adhesive joint and diffuses throughout the immersion period. Figure 4 shows the penetration of water as a function of the immersion time. Due to the chemical action of the absorbed water, some clearly delineated zones can be observed, which mark the limit to which absorbed water has irreversibly changed the polymer structure during the time considered. The darker zones are regions where water has not attacked by hydrolysis the polymer chains; that is, the concentration of water has been at all times below the critical concentration (which causes irreversible changes in the polymer). The water absorbed by the adhesive produces microstructural changes in the polymer due to the hydrolysis of certain macromolecular functional groups. The functional groups responsible for these chemical changes were identified by FTIR and will be presented later in this paper. These morphological changes are translated into losses of mechanical properties that have been investigated by creep tests on specimens Mixed Cantilever Beam (MCB) at different temperatures. After 180 days of immersion of the specimens, it was concluded that 

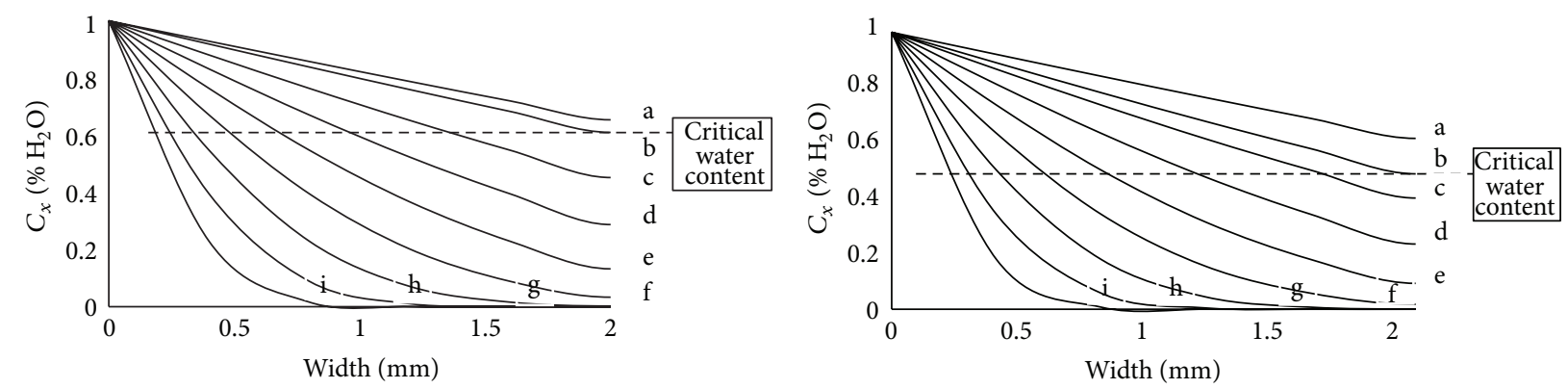
(a) 180 days
(f) 8 days
(b) 139 days
(g) 4 days
(c) 64 days
(h) 2 days
(d) 32 days
(i) 1 day
(e) 16 days

(a)
(a) 180 days
(f) 8 days
(b) 94 days
(c) 64 days
(d) 32 days
(g) 4 days
(h) 2 days
(i) 1 day

(e) 16 days

(b)

FIGURE 3: Concentration profiles of seawater in MCB test specimens as a function of immersion time: (a) polyurethane and (b) vinylester.

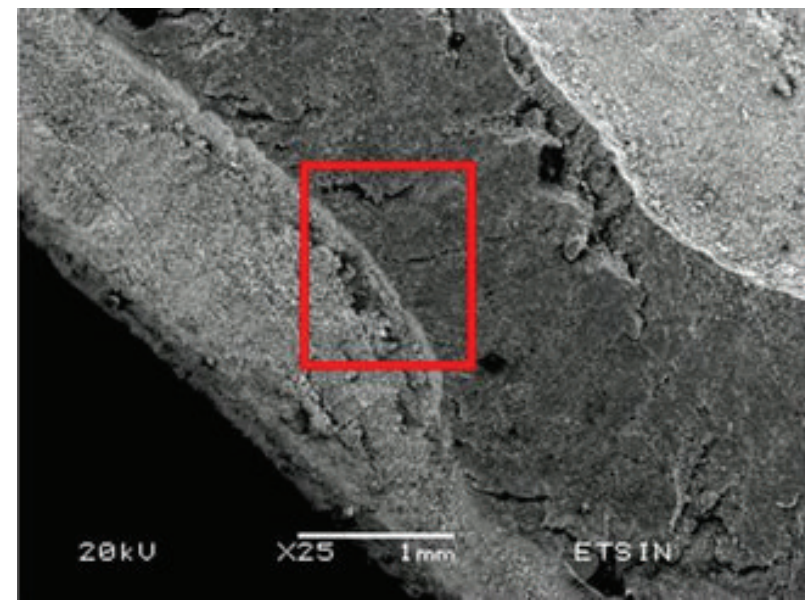

(a)

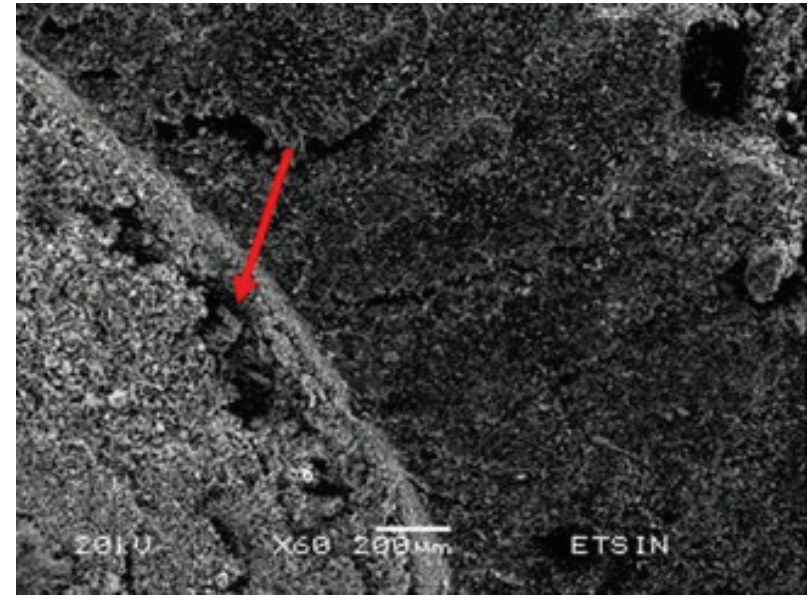

(b)

FIGURE 4: SEM image of the surface of polyurethane adhesive MCB specimens after fracture. Following a 32-day seawater immersion period, (a) the limit of the water diffusion zone and (b) a detailed image of the adhesive's degradation produced by the action of water.

the $J$-integral value (depending on the strain) implies a loss of stiffness of $51 \%$ and a decrease in the failure load of $59 \%$ for the adhesive tested.

Upon more careful observation of the adhesive surface (Figure 5), three well-differentiated zones can be identified, which are related to the water concentration reached and the chemical changes caused in the polymer.

(i) Zone 1 is where the absorbed water has not exceeded the critical concentration of water, and therefore the initial properties of the adhesive remain unchanged.

(ii) Zone 2 is the region to which seawater has penetrated and concentrations were above the critical concentration, chemically linked to the polymer, and the polymer properties are irreversibly degraded.

(iii) Zone 3 is the region in which salt deposits occur because the solubility product of dissolved salts in seawater has been reached locally. These deposits constitute a physical barrier to the ingress of water.

Polyurethane can absorb water to approximately $0.6 \%$ before irreversible degradation takes place. In Figure 5(a), this limit corresponds to Zone 3. Upon closer SEM inspection, saline residues are visible on the polymeric network, which block the slide of macromolecules until the material cannot be deformed and finally fails under the loads placed on it (Figure 6). Tests have been performed for the diffusion of distilled and demineralized water in the polymer, and subsequently we have used natural seawater. In this case, the diffusion coefficients are slightly smaller. Since the water molecule is of the same size in both cases and the same average size of the polymer network and considering that has been cured in standard conditions, we propose the following hypothesis: decreases in the diffusion coefficients can be due to the action of saline sediments present in the polymer 


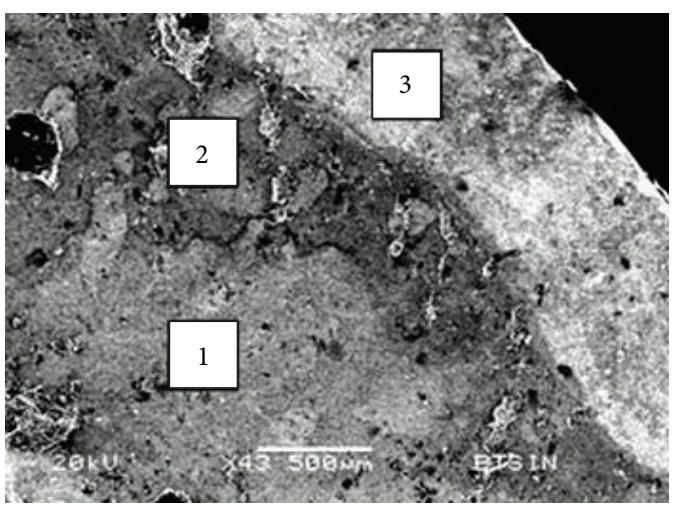

(a)

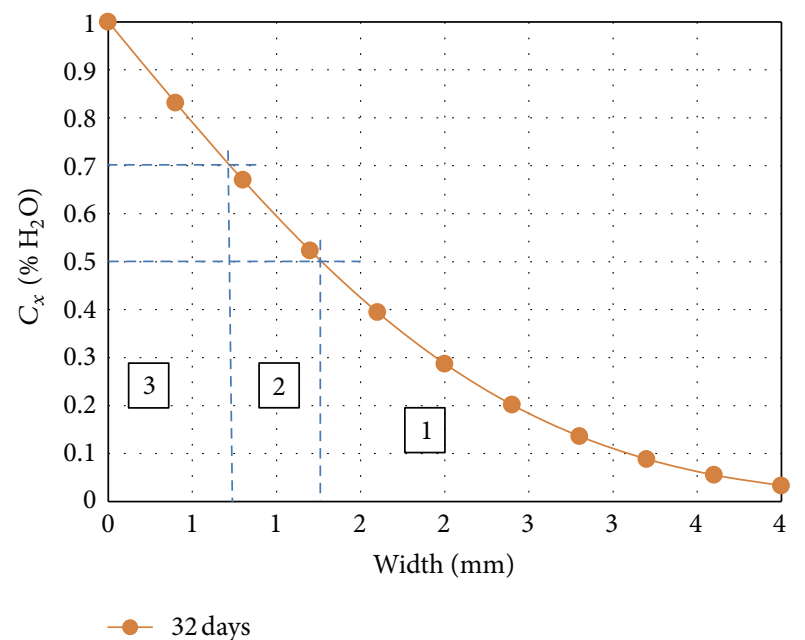

(b)

FIGURE 5: (a) SEM image of the surface of the polyurethane adhesive MCB specimens after fracture following a 32-day immersion period in seawater. (b) Different zones as a function of water concentration.

network. This working hypothesis is based on the discrepancy of the diffusion coefficients. Indeed, it may cause precipitation of the salt compounds during the drying period in vacuum but, during the diffusion process can produce a precipitation localized because of the difficulty of homogenization of the salt concentration at each sampling point, as diffusive flow imposes a gradient in the concentration of water: the water molecules continue to advance so that the salt concentration increases in the zones that are being left behind until it exceeds the solubility product and the precipitated appears. This precipitated acts as a physical barrier to the entry of more water in the polymer.

The fracture of the vinylester zone 3 material is shown in Figure 7, and it is different from that observed in polyurethane. After 32 days of water absorption, the water retained swells the macromolecular network, which causes tears in the material, together with a selective attack on some functional groups. This damage is permanent and is linked to reach a critical water content and to generate sufficiently high tension forces in the polymer to produce a fracture. The material experiences an irreversible degradation of its

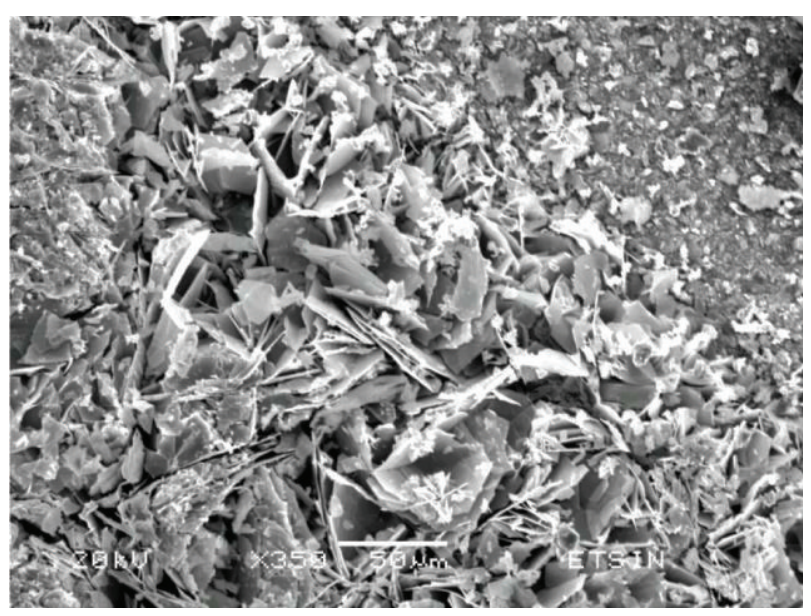

FIGURE 6: SEM image of the saline deposits on the polyurethane adhesive.

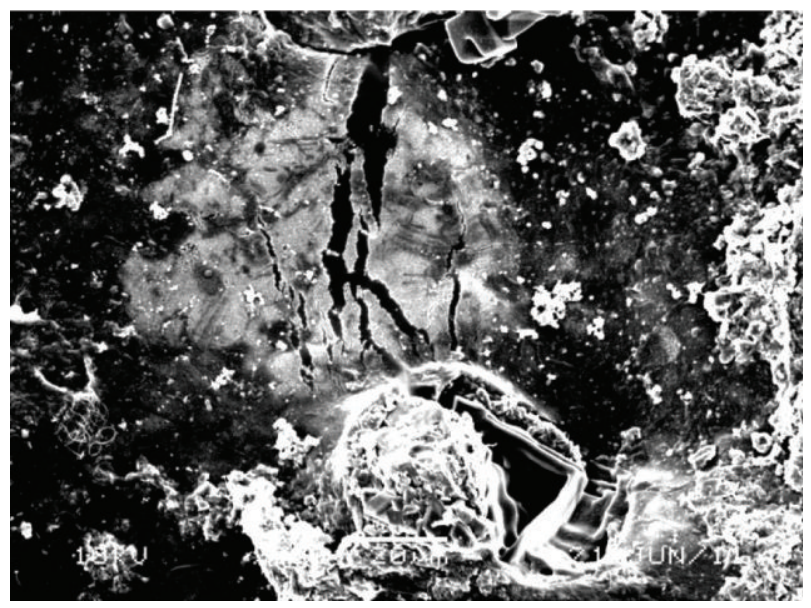

FIGURE 7: SEM image of vinylester resin with details of the blistering caused by a 32-day immersion in seawater.

mechanical properties, as shown by the mechanical tests performed, as will be discussed later.

The quantification of these phenomena would require mechanical tests in different humidity environments at different temperatures and with several levels of tension applied over the adhesive joint.

3.3. Infrared Spectroscopy. FTIR spectroscopy was performed to study the chemical changes that have been produced in the adhesive throughout the degradation process.

Figure 8(a) shows the polyurethane adhesive FTIR spectrum. In order to know the initial state of the adhesive, tests have been made with the adhesive intact, that is, without immersion in water.

The bands at 2934 and $2862 \mathrm{~cm}^{-1}$ correspond to the C$\mathrm{H}$ stretching in the polyurethane, and the bands due to $\mathrm{N}-\mathrm{H}$ are found at 3334 and $1530 \mathrm{~cm}^{-1}$. Other absorption bands are $\mathrm{N}-\mathrm{H}$ plane $\left(1168 \mathrm{~cm}^{-1}\right)$ and $\mathrm{N}-\mathrm{H}$ out-of-plane deformations $\left(734 \mathrm{~cm}^{-1}\right)$. The band at $1724 \mathrm{~cm}^{-1}$ corresponds 


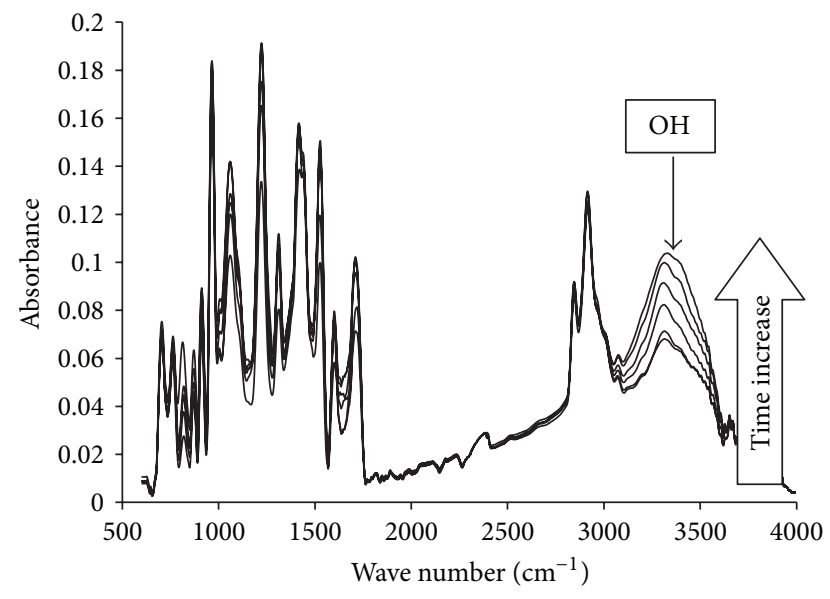

(a)

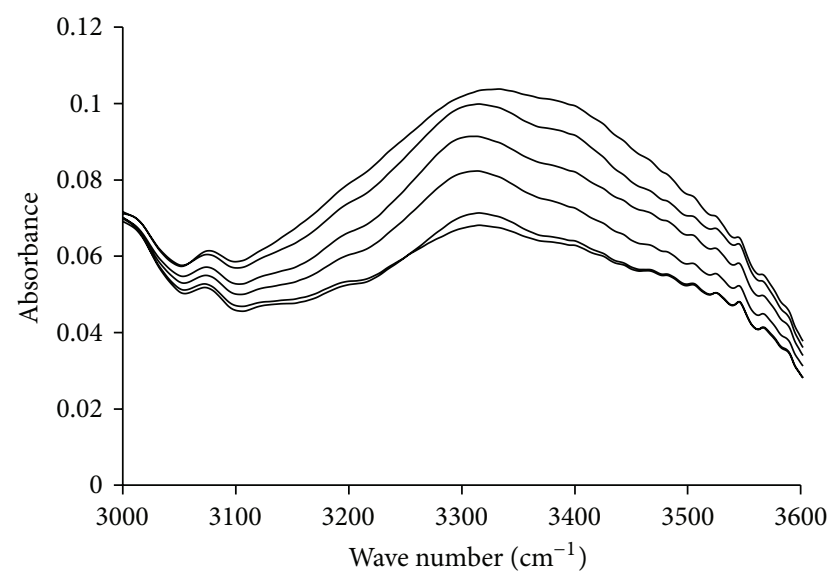

(b)

FIGURE 8: IR spectrogram: (a) polyurethane and (b) details of band $3400 \mathrm{~cm}^{-1}$.

to the $\mathrm{C}=\mathrm{O}$ stretching of urethane, and the bands at 1261 and $970 \mathrm{~cm}^{-1}$ are due to $\mathrm{C}-\mathrm{N}$ stretching and $\mathrm{C}-\mathrm{O}-\mathrm{C}$ in urethane, respectively. Furthermore, the bands at 1219 and $1073 \mathrm{~cm}^{-1}$ correspond to antisymmetrical and symmetrical $\mathrm{N}-\mathrm{C}=\mathrm{O}$ stretching, respectively $[31,32]$. The absorption band located within the 3400 to $3500 \mathrm{~cm}^{-1}$ range corresponds to the $\mathrm{O}-\mathrm{H}$ linked by hydrogen bridges or to different groups linked to molecular water through hydrogen bonds. It is observed that, with an increase in the immersion time, the $\mathrm{N}-\mathrm{H}$ band stretching changes to higher frequency values due to the water absorbance that is occurring [27].

Figure 9(a) shows the FTIR spectrum of vinylester. The band at $3416 \mathrm{~cm}^{-1}$ corresponds to the $\mathrm{O}-\mathrm{H}$ stretching vibrations in the vinylester. The band at $3036 \mathrm{~cm}^{-1}$ corresponds to the $\mathrm{C}-\mathrm{H}$ stretch of the benzene ring, and the bands due to $\mathrm{C}=\mathrm{C}$ are found at 1635 and $940 \mathrm{~cm}^{-1}$. Another absorption band due to benzene is at $1889 \mathrm{~cm}^{-1}$, which corresponds to aromatic ring vibration, while the aromatic ring stretch is at $1581 \mathrm{~cm}^{-1}$. The band at $1712 \mathrm{~cm}^{-1}$ corresponds to the $\mathrm{C}=\mathrm{O}$ stretching, and the bands at 1233 and $1160 \mathrm{~cm}^{-1}$ are due to $\mathrm{C}-\mathrm{O}-\mathrm{C}$ and $\mathrm{C}-\mathrm{CO}-\mathrm{O}$ stretching, respectively. Furthermore,

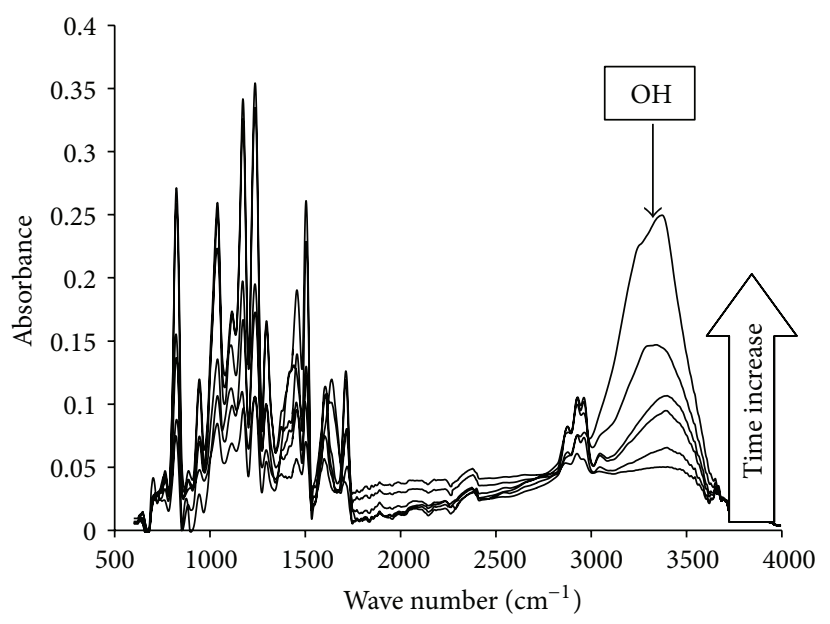

(a)

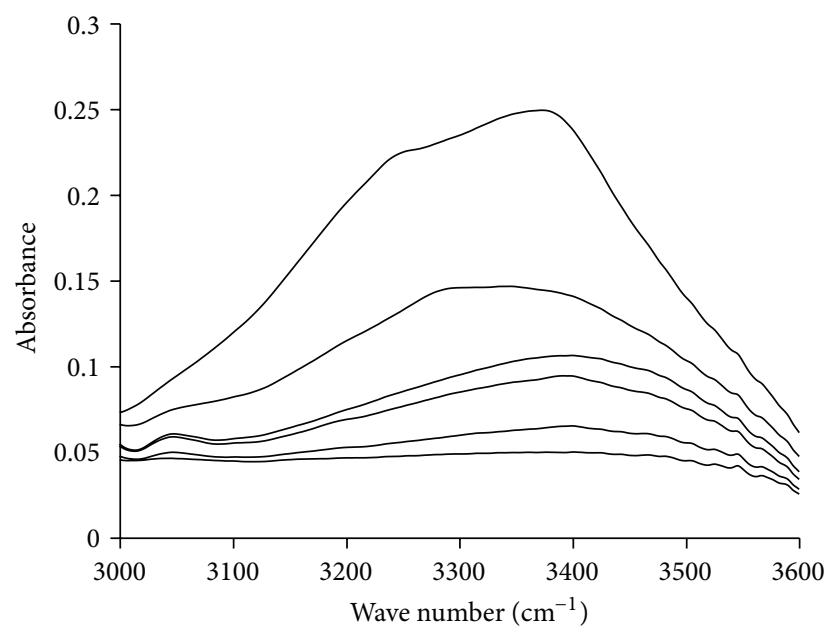

(b)

FIGURE 9: IR spectrogram: (a) vinylester and (b) details of band $3400 \mathrm{~cm}^{-1}$.

the bands at 1038 and $767 \mathrm{~cm}^{-1}$ correspond to aromatic C$\mathrm{H}$ bending and aromatic ring stretch, respectively [33]. As in the case of the polyurethane adhesive, an absorption band located within the 3400 to $3500 \mathrm{~cm}^{-1}$ range is observed after immersion in seawater, which corresponds to $\mathrm{O}-\mathrm{H}$ groups linked by hydrogen bridges or to other groups linked to molecular water through hydrogen bonds. An increase in frequency is also observed in the 3400 to $3500 \mathrm{~cm}^{-1}$ band due to the formation of hydrogen bonds [27].

The analysis of the polyurethane adhesive samples throughout the degradation period did not show significant changes from the reference spectrum, except for an increase in the $3400 \mathrm{~cm}^{-1}$ band as the immersion time increases, which corresponds to the $\mathrm{O}-\mathrm{H}$ groups linked by hydrogen bridges due to the water absorption that occurs. However, the vinylester resin spectral analysis shows many changes throughout the immersion period, which indicates the many degradation processes that occur; this result was expected because vinylester resin is a crosslinked polymer. As in the 
Under dry condition<smiles>CC(=O)NCOC(C)=O</smiles>

After immersion in room temperature water

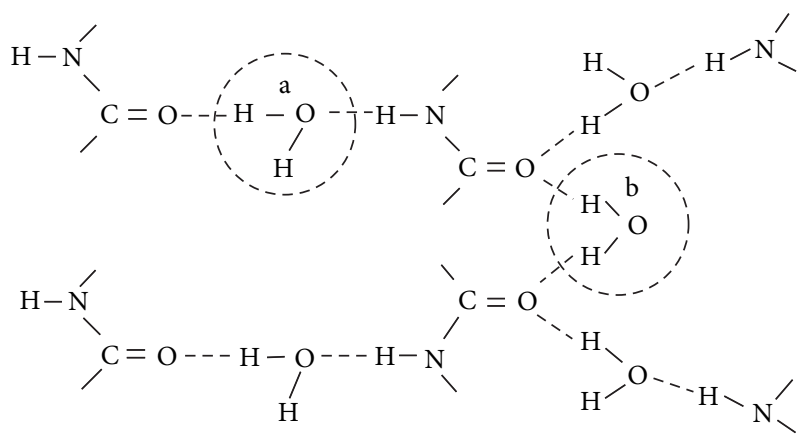

FIGURE 10: Effects of water on the hydrogen bonding in polyurethane SMP [27].

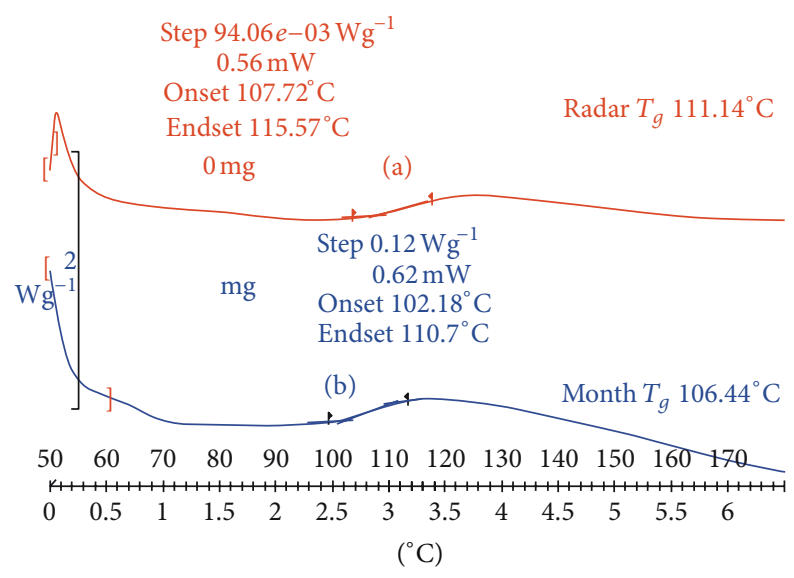

FIGURE 11: DSC of a $5 \mathrm{mg}$ vinylester sample: (a) pristine sample and (b) after 9 months of degradation.

polyurethane adhesive, an increase in the $3400 \mathrm{~cm}^{-1}$ band occurs due to the hydrolysis that is experienced, which becomes more pronounced as the immersion time increases.

A broadening of the peak corresponding to the $3400 \mathrm{~cm}^{-1}$ band for each of the polymers is shown in Figures 8(b) and 9(b). This band is caused by the entry of water. In the case of polyurethane joins $\mathrm{NH}$ groups and is chemically bound. It is responsible for the degradation of the mechanical properties. Figure 10 shows the effect of water on the chemical structure of the polyurethane.

3.4. Differential Scanning Calorimetry (DSC). Through differential scanning calorimetry, the change in the glass transition temperature $\left(T_{g}\right)$ was observed in the different degradation periods. Figure 11 shows the DSC traces for a pristine vinylester resin sample and a sample after 9 months of immersion. The glass transition temperature is determined automatically by the computer control software, which determines the midpoint between the two marks indicated on the curve. This midpoint corresponds to $T_{g}$ for each sample analyzed.

A reduction in the glass transition temperature value is observed after 9 months of degradation in seawater $\left(T_{g}\right.$ of a pristine sample $=111.41^{\circ} \mathrm{C}$ and $T_{g}$ after 9 months of degradation $=106.44^{\circ} \mathrm{C}$ ). It is also observed that the vinylester resin without degradation is stable until approximately $180^{\circ} \mathrm{C}$; after 9 months of degradation, however, it does not stabilise, and instead it drops continuously after the glass transition, indicating that additional degradation is taking place during heating. Significant changes in the polyurethane glass transition temperatures are not observed after a long immersion time due to the high pigmentation of polymer, which makes $T_{g}$ acquisition difficult.

3.5. Tensile Test. The results of the tensile test are shown in Figure 12. A reduction in the mechanical properties was observed after a long immersion time in natural seawater for both resins. In the vinylester resin, the tensile strength decreases from $120.95 \mathrm{~N}$ before immersion to $107 \mathrm{~N}$ after 9 months of immersion in seawater. For polyurethane, the decrease in tensile strength is from $24.81 \mathrm{~N}$ before immersion to $19.7 \mathrm{~N}$ after 9 months of immersion. Degradation of the resin molecular structure clearly occurs, causing irreversible damage and a reduction of the mechanical properties. A tension test alone is not enough to fully characterise the loss in mechanical strength experienced by the adhesive as a result of the degradation caused by exposure to seawater. The polymers have some viscoelastic behaviour, and the tensile test results do not reflect the loss in resistance capacity under constant loads applied over long-time periods. The performance of creep assays.is precise.

\section{Conclusions}

(i) The water concentration profiles in adhesive joints were determined for both polyurethane and vinylester adhesives using diffusion coefficients calculated via gravimetric methods. The diffusion coefficient is $6.39 \times 10^{-13} \mathrm{~m}^{2} \mathrm{~s}^{-1}$ for polyurethane and $5.14 \times$ $10^{-13} \mathrm{~m}^{2} \mathrm{~s}^{-1}$ for the vinylester. According to these values, the time required for the water concentration in the central zone to exceed a critical value, above which irreversible damage in the polymer occurs, can be determined.

(ii) The microstructural changes in the polymers due to the hydrolytic action of water were observed by scanning electron microscopy (SEM), and three distinct zones corresponding to different water concentrations reached and the chemical modifications caused in the polymer were identified. 


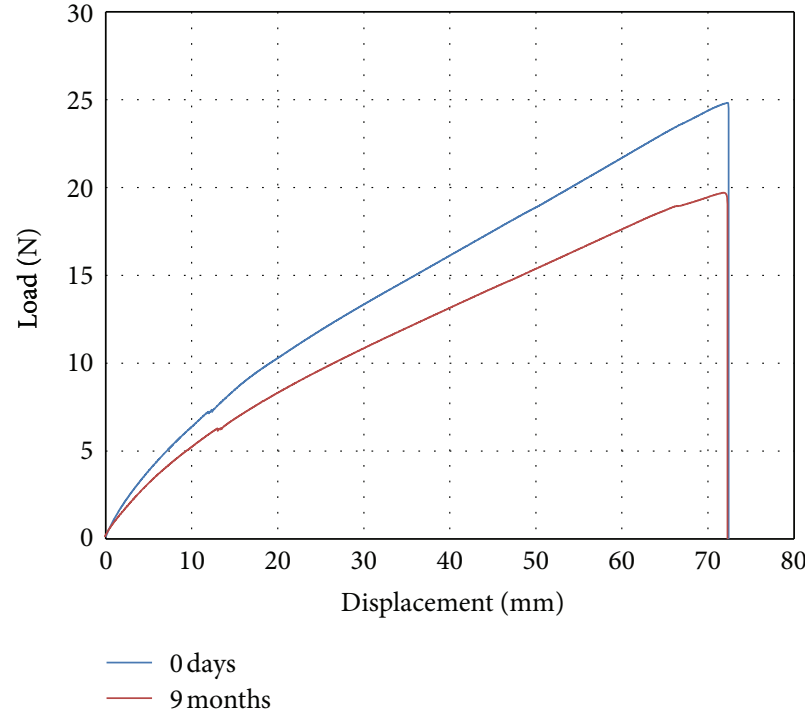

(a)

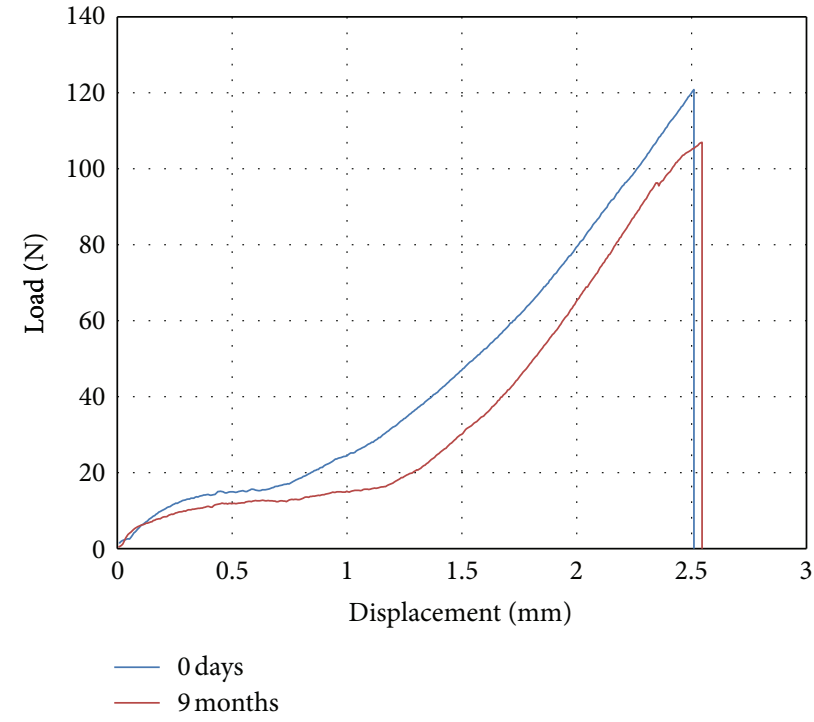

(b)

FIGURE 12: Tensile test load-displacement plots for (a) polyurethane and (b) vinylester.

(iii) In the infrared absorption (FTIR) spectra of both polymers, increases in the $3400 \mathrm{~cm}^{-1}$ band corresponding to bonded $\mathrm{OH}$ groups were observed; this increase was attributed to water absorption in the polymeric network with increasing immersion time.

(iv) In the vinylester resin FTIR spectrum, large changes in several other spectral bands occur throughout the degradation period, which indicates a relatively greater alteration of the polymer molecular structure. Hydrolytic attack to different functional groups of the molecule appears to result in faster degradation and a greater final water concentration inside the polymer network than with polyurethane.

(v) A reduction of the vinylester resin glass transition temperature from a pristine sample to one subjected to nine months of degradation was observed using DSC. In addition, a continuous decrease in the curve after the glass transition was observed, indicative of further degradation. An appreciable change in the glass transition temperature of polyurethane was not observed.

(vi) The creep tests (that were carried out with MCB specimens) have allowed us to calculate the loss in stiffness and strength of the adhesive joints in function of immersion time in natural seawater. In this way, we calculated the evolution of the $J$-integral in function of the strain of the adhesive during the testing time. In the case of polyurethane, we calculated a decrease of $51 \%$ in stiffness and a $59 \%$ in strength.

\section{Acknowledgments}

The authors would like to thank the Madrid Polytechnic University (Universidad Politécnica de Madrid) for the project
$\mathrm{N}^{\circ} 123$ and the TEKHIMAT company for the funding received for carrying out these tests. They would also like to express their gratitude to the laboratory technical staff: Mr. José Illescas, Ms. Ana Soria, and Ms. Ana García.

\section{References}

[1] M. A. Herreros, J. C. Suárez, P. Pinilla, S. Miguel, F. López, and I. D. de Ulzurrun, "MaLECoN: a new laminated fibermetal hybrid for shipbuilding," in Proceedings of the 47th Naval Engineering and Maritime Industry Congress, Palma de Mallorca, Spain, 2008.

[2] M. Fernando, W. W. Harjoprayitbi, and A. J. Kinloch, "A fracture mechanics study of the influence of moisture on the fatigue behaviour of adhesively bonded aluminium-alloy joints," International Journal of Adhesion and Adhesives, vol. 16, no. 2, pp. 113-119, 1996.

[3] J. Sargent, "Durability studies for aerospace applications using peel and wedge tests," International Journal of Adhesion and Adhesives, vol. 25, no. 3, pp. 247-256, 2005.

[4] G. Doyle and R. A. Rethrick, "Environmental effects on the ageing of epoxy adhesive joints," International Journal of Adhesion and Adhesives, vol. 29, no. 1, pp. 77-90, 2009.

[5] T. Andersson and U. Stigh, "The stress-elongation relation for an adhesive layer loaded in peel using equilibrium of energetic forces," International Journal of Solids and Structures, vol. 41, no. 2, pp. 413-434, 2004.

[6] A. Sen, M. Bhattacharya, K. A. Stelson, and V. R. Voller, "Creep in injection molded starch/synthetic polymer blends," Materials Science and Engineering A, vol. 338, no. 1-2, pp. 60-69, 2002.

[7] J. D. Minford, "Comparative aluminium joint evaluations in varying saltwater exposure conditions," The Journal of Adhesion, vol. 18, no. 1, pp. 19-24, 1985.

[8] C. Liljedahl, A. Crocombe, M. Wahab, and I. Ashcroft, "Modelling the environmental degradation of adhesively bonded aluminium and composite joints using a CZM approach," 
International Journal of Adhesion and Adhesives, vol. 27, no. 6, pp. 505-518, 2007.

[9] X. Buch and M. E. R. Shanahan, "Thermal and thermooxidative ageing of an epoxy adhesive," Polymer Degradation and Stability, vol. 68, no. 3, pp. 403-411, 2000.

[10] F. Ellyin and C. Rohrbacher, "Effect of aqueous environment and temperature on glass-fibre epoxy resin composites," Journal of Reinforced Plastics and Composites, vol. 19, no. 17, pp. 14051427, 2000.

[11] A. Aktas and I. Uzun, "Sea water effect on pinned-joint glass fibre composite materials," Composite Structures, vol. 85, no. 1, pp. 59-63, 2008.

[12] C. Wood and W. L. Bradley, "Determination of the effect of seawater on the interfacial strength of an interlayer Eglass/graphite/epoxy composite by in situ observation of transverse cracking in an environmental SEM," Composites Science and Technology, vol. 57, no. 8, pp. 1033-1043, 1997.

[13] M. Rutkowska, K. Krasowska, A. Heimowska, I. Steinka, and H. Janik, "Degradation of polyurethanes in sea water," Polymer Degradation and Stability, vol. 76, no. 2, pp. 233-239, 2002.

[14] P. Davies and G. Evrard, "Accelerated ageing of polyurethanes for marine applications," Polymer Degradation and Stability, vol. 92, no. 8, pp. 1455-1464, 2007.

[15] V. Barron, M. Buggy, A. Mas, and F. Schue, "Durability of APC2/Polyurethane adhesive joints for biomedical applications," International Journal of Adhesion and Adhesives, vol. 20, no. 5, pp. 361-366, 2000.

[16] A. Kootsookos and A. P. Mouritz, "Seawater durability of glass- and carbon-polymer composites," Composites Science and Technology, vol. 64, no. 10-11, pp. 1503-1511, 2004.

[17] M. R. Bowditch, "The durability of adhesive joints in the presence of water," International Journal of Adhesion and Adhesives, vol. 16, no. 2, pp. 73-79, 1996.

[18] J. Burns, P. S. Dubbelday, and R. Y. Ting, "Dynamic bulk modulus of various elastomers," Journal of Polymer Science B, vol. 28, no. 7, pp. 1187-1205, 1990.

[19] W. Possart, "Chemical structura formation and morphology in ultrathin polyurethane films on metals," in Adhesion, Current Research and Applications, vol. 6, pp. 71-88, WILEY-VCH, Weinheim, Germany, 2005.

[20] P. Davies, F. Mazéas, and P. Casari, "Sea water aging of glass reinforced composites: shear behaviour and damage modelling," Journal of Composite Materials, vol. 35, no. 15, pp. 1343-1372, 2001.

[21] J. Raghavan and M. Meshii, "Creep rupture of polymer composites," Composites Science and Technology, vol. 57, no. 4, pp. 375-388, 1997.

[22] E. Woo, "Moisture-temperature equivalency in creep analysis of a heterogeneous-matrix carbon fibre/epoxy composite," Composites, vol. 25, no. 6, pp. 425-430, 1994.

[23] D. J. O'Brien, P. T. Mather, and S. R. White, "Viscoelastic properties of an epoxy resin during cure," Journal of Composite Materials, vol. 35, no. 10, pp. 883-904, 2001.

[24] J. C. Suárez, C. Alia, M. V. Biezma, P. Pinilla, and J. M. Arenas, "Long term ageing of adhesives for hybrid materials in seawater," in Proceedings of the 9th European Adhesion Conference (EURADH '12), p. 44, Friedrichshafen, Germany, 2012.

[25] D. A. Dillard, Advances in Structural Adhesive Bonding, Woodhead, 2010.
[26] J. Crank and G. S. Park, Diffusion in Polymers, Academic Press, 1968.

[27] B. Yang, W. M. Huang, C. Li, and L. Li, "Effects of moisture on the thermomechanical properties of a polyurethane shape memory polymer," Polymer, vol. 47, no. 4, pp. 1348-1356, 2006.

[28] N. V. Datla, M. Papini, J. Ulicny, B. Carlson, and J. K. Spelt, “The effects of test temperature and humidity on the mixed-mode fatigue behavior of a toughened adhesive aluminum joint," Engineering Fracture Mechanics, vol. 78, no. 6, pp. 1125-1139, 2011.

[29] J. Högberg and U. Stigh, "Specimen proposals for mixed mode testing of adhesive layer," Engineering Fracture Mechanics, vol. 73, no. 16, pp. 2541-2556, 2006.

[30] J. C. Suárez, P. Pinilla, F. López, M. A. Herreros, and M. V. Biezma, "Mixed mode double cantilever beams test specimen for characterization of structural adhesive joints," Anales De Mecánica De Fractura, vol. 27, p. 685, 2010.

[31] R. Torregrosa, S. Álvarez, and J. M. Martín, “Migration of low molecular weight moiety at rubber-polyurethane interface: an ATR-IR spectroscopy study," International Journal of Adhesion and Adhesives, vol. 31, no. 6, pp. 389-397, 2011.

[32] M. Bassyouni, S. A. Sherif, M. A. Sadek, and F. H. Ashour, "Synthesis and characterization of polyurethane-treated waste milled light bulbs composites," Composites B, vol. 43, no. 3, pp. 1439-1444, 2011.

[33] N. Jost and J. Karger-Kocsis, "On the curing of a vinylesterurethane hybrid resin," Polymer, vol. 43, no. 4, pp. 1383-1389, 2001. 

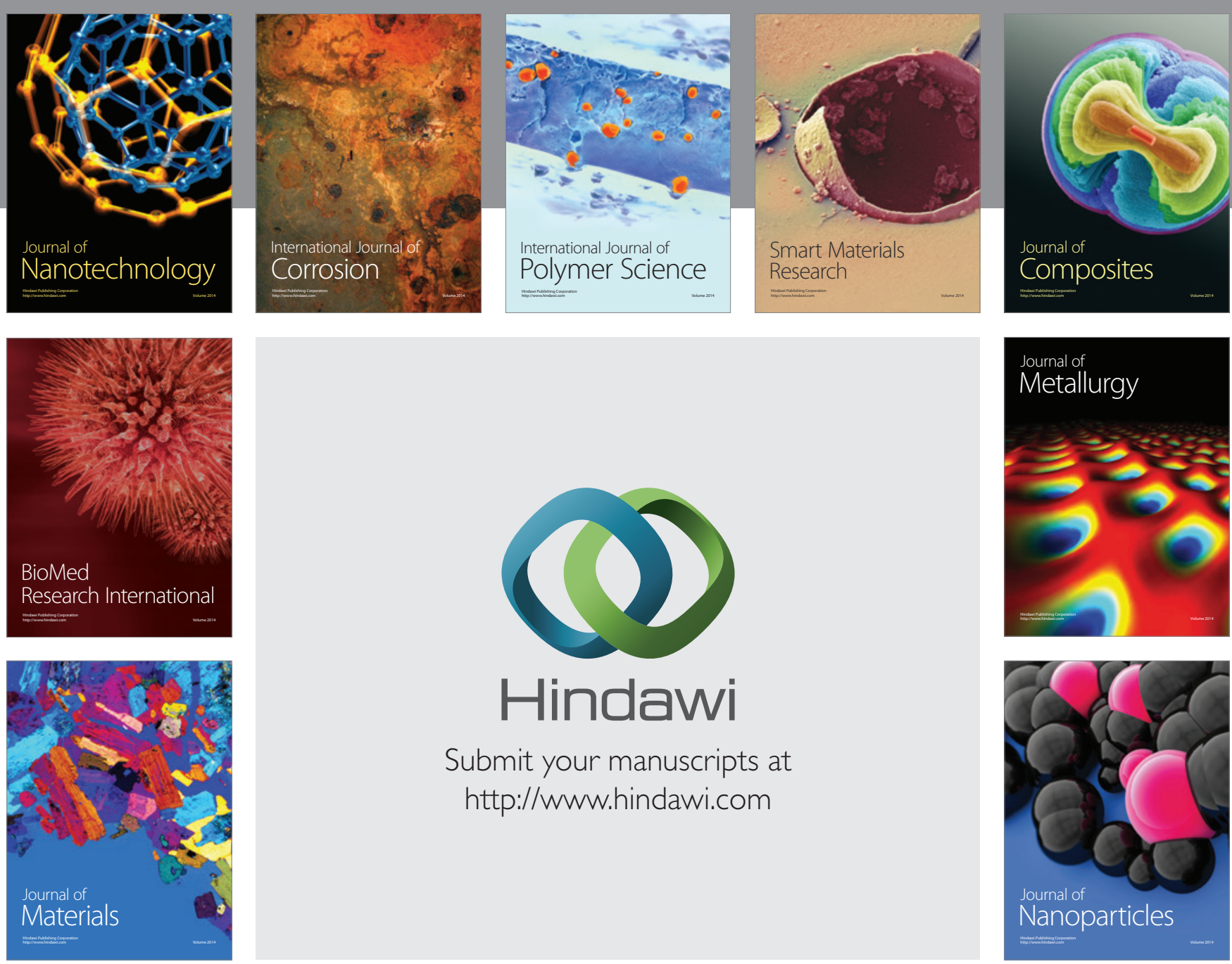

Submit your manuscripts at http://www.hindawi.com
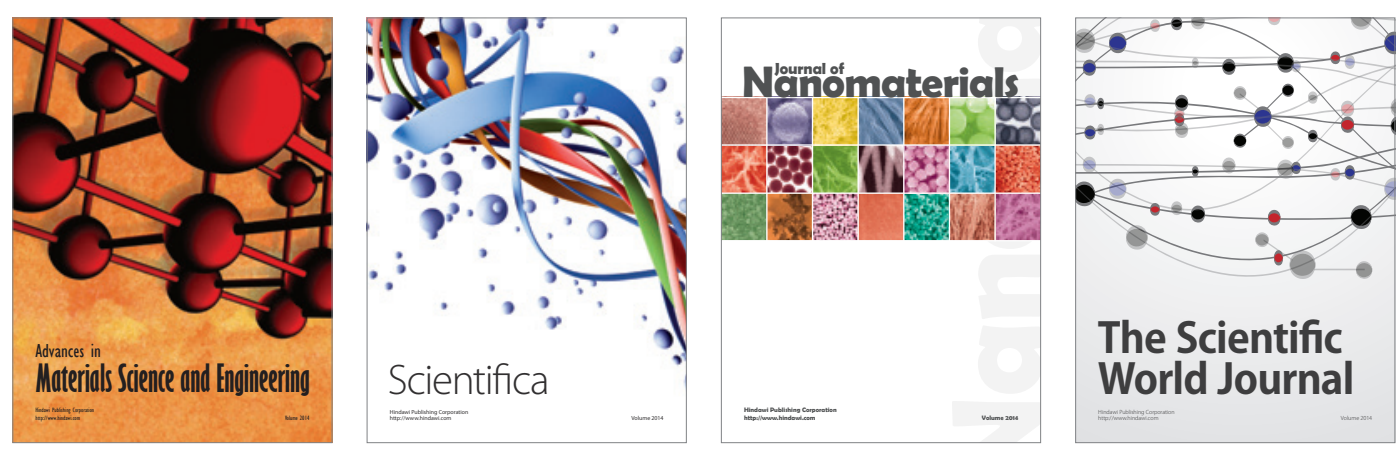

\section{The Scientific World Journal}
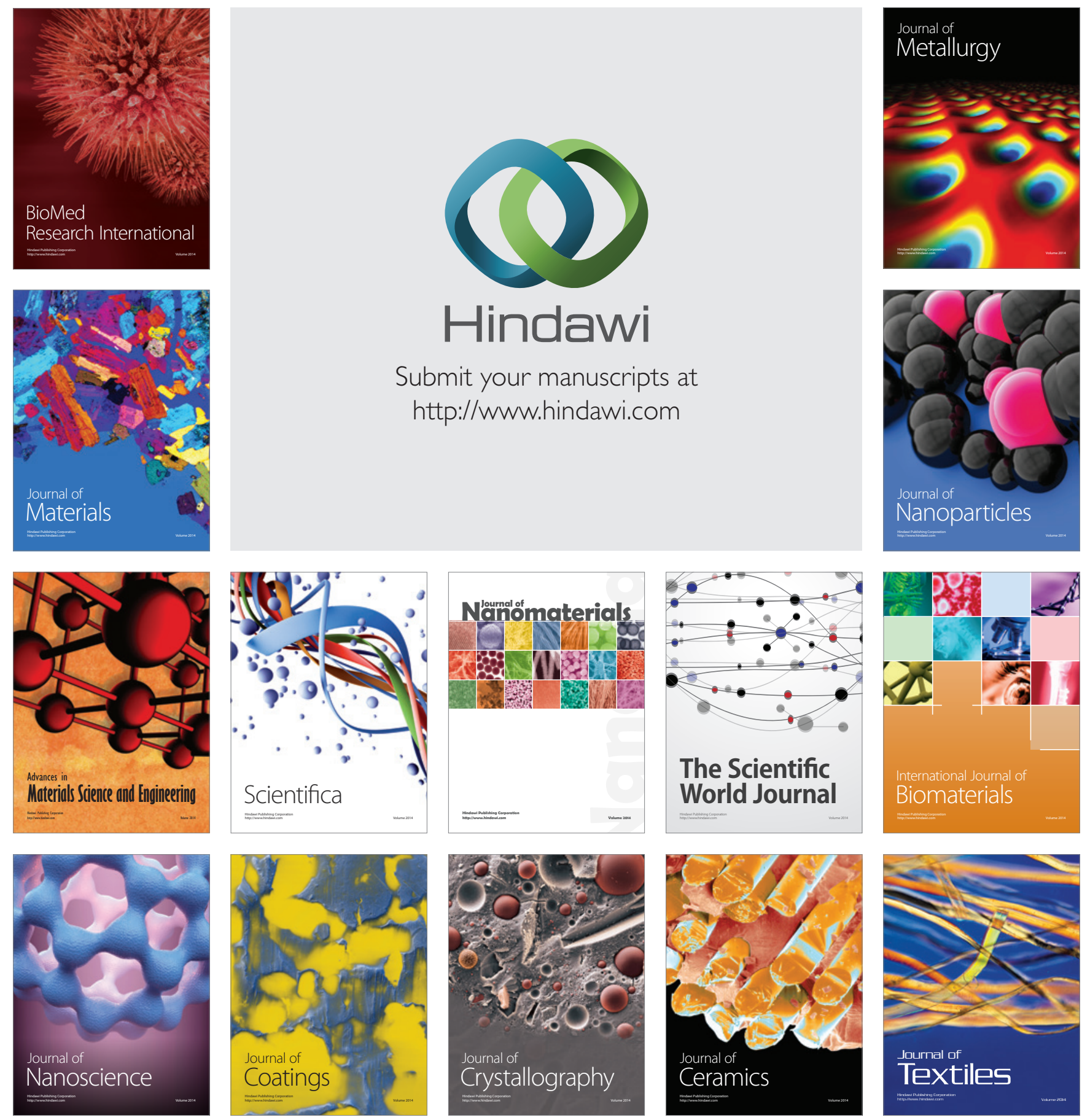